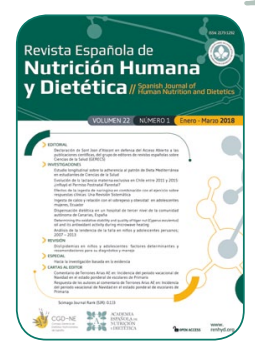

\title{
CARTA AL EDITOR \\ Respuesta de los autores al comentario de Terrones Arias AE en: Incidencia del periodo vacacional de Navidad en el estado ponderal de escolares de Primaria
}

\author{
Melchor Martínez-Redondo ${ }^{a, *}$, Pedro Ángel Latorre-Román ${ }^{a}$

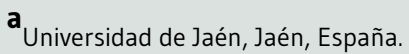 \\ *melchor_mr@hotmail.com
}

Editor Asignado: Rodrigo Martínez-Rodríguez. Universidad de Murcia. Murcia, España.

Recibido el 14 de marzo de 2018; aceptado el 16 de marzo de 2018; publicado el 18 de marzo de 2018.

\section{CITA}

Martínez-Redondo M, Latorre-Román PA. Respuesta de los autores al comentario de Terrones Arias AE en: Incidencia del periodo vacacional de Navidad en el estado ponderal de escolares de Primaria. Rev Esp Nutr Hum Diet. 2018; 22(1): 103-4. doi: 10.14306/renhyd.22.1.574

Estimados Señores: Hemos recibido su comentario sobre "Incidencia del periodo vacacional de Navidad en el estado ponderal de escolares de Primaria"1 donde aparecen los comentarios sobre nuestro trabajo. Agradecemos los mismos y a continuación intentamos dar respuesta a ellos con la finalidad de aclarar lo mejor posible estas cuestiones de nuestro estudio.

Entendemos que la palabra "incidencia" tiene diferentes acepciones según el Diccionario de la Real Academia Española (RAE), exactamente 5 acepciones, siendo una de ellas como bien indican "número de casos ocurridos" (acepción 2 RAE). En nuestro estudio, la palabra "incidencia" hace referencia a la acepción 3 de la RAE, donde se define como "influencia o repercusión"; es decir, el efecto, consecuencia o cambio que produce una cosa en otra. Por lo tanto, teniendo en cuenta la acepción 3, consideramos que la palabra "incidencia" que aparece en el título de este trabajo indica la repercusión o efecto que causa las vacaciones de Navidad sobre el estado ponderal de los escolares de Primaria.

Respecto al segundo comentario, " $p$ " es un valor que por una cuestión formal consideramos importante aportarlo en todas las variables.

En cuanto al resultado de la prueba ANOVA, los datos de este estudio se han hallado mediante el programa estadístico SPSS., v.19.0 para Windows, (SPSS Inc, Chicago, USA). Dicho programa nos ofreció esos resultados. 
Rev Esp Nutr Hum Diet. 2018; 22(1): 103 - 104

Respuesta de los autores al comentario de Terrones Arias AE en: Incidencia del periodo vacacional de Navidad en el estado ponderal de escolares de Primaria

\section{CONFLICTO DE INTERESES}

Los autores del presente manuscrito son autores del artículo original comentado por Terrones Arias AE.

\section{REFERENCIAS}

(1) Terrones Arias AE. Comentario de Terrones Arias AE en: Incidencia del periodo vacacional de Navidad en el estado ponderal de escolares de Primaria. Rev Esp Nutr Hum Diet. 2018; 22(1): 103-4. 